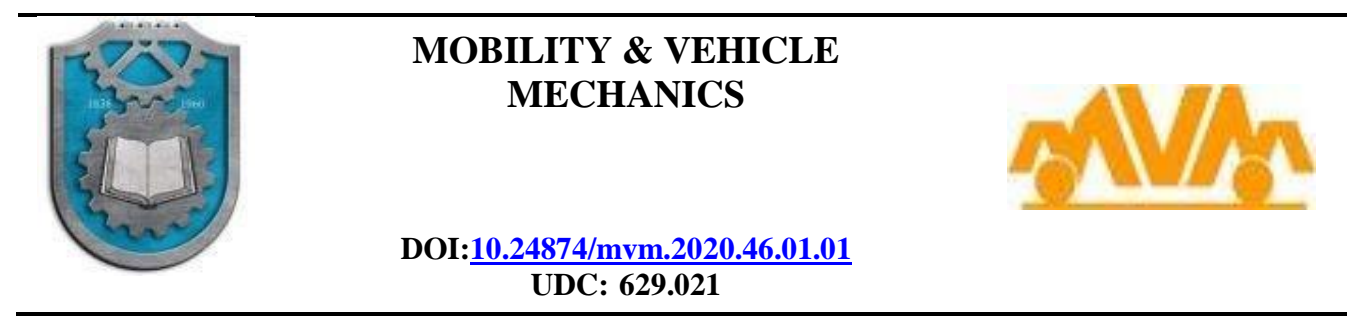

\title{
DESIGN METHOD FOR HYDRODYNAMIC TORQUE CONVERTER
}

\author{
Dobrica Milovanović ${ }^{1 *}$, Dušan Gordić ${ }^{2}$, Vladimir Vukašinović ${ }^{3}$, Mladen Josijević ${ }^{4}$
}

Received in February $2020 \quad$ Accepted in March 2020

RESEARCH ARTICLE

\begin{abstract}
The design of hydrodynamic torque converter impeller is a complex problem that can be solved if the whole set of individual steps is carried out, starting from input data selection to determination of the model sections of the blade. For that reason, fast as well as efficient solution of inverse flow problem can be carried out only by using numerical techniques to solve fluid flow problems. The method developed in this paper, based on free vortex design, involves the linking of meridional and blade-to-blade solutions. A basic assumption used for predicting flow in the meridional plane of the hydrodynamic transmissions impeller is an axisymmetric flow. In accordance with the Bauersfeld method, the design of the impeller blade is performed in an iterative manner using the relationships between velocity components and geometrical blade parameters. Particular attention in the paper is paid to the determination of a functional law of the energy interchange from the inlet to the outlet in the pump and turbine impeller in hydrodynamic transmissions. Finally, a design example for the pump impeller blade is presented.
\end{abstract}

KEY WORDS: torque converter, axisymmetric flow, energy interchange, design, blade

C 2020 Published by University of Kragujevac, Faculty of Engineering

\footnotetext{
${ }^{I}$ Dobrica Milovanović, PhD, full prof., University of Kragujevac, Faculty of Engineering, Sestre Janjić 6, 34000 Kragujevac, Serbia, dobrica@kg.ac.rs (*Corresponding author)

${ }^{2}$ Dušan Gordić, PhD, full prof., University of Kragujevac, Faculty of Engineering, Sestre Janjić 6, 34000 Kragujevac, Serbia, gordic@kg.ac.rs

${ }^{3}$ Vladimir Vukašinović, PhD, assist. prof., University of Kragujevac, Faculty of Engineering, Sestre Janjić 6, 34000 Kragujevac, Serbia, vladimir.vukasinovic@kg.ac.rs

${ }^{4}$ Mladen Josijević, Assistant, University of Kragujevac, Faculty of Engineering, Sestre Janjić 6, 34000 Kragujevac, Serbia, mladen.josijevic@fink.rs
} 


\section{METOD PROJEKTOVANJA HIDRODINAMIČKIH TRANSMISIJA}

REZIME: Projektovanje radnih kola hidrodinamičkih transmisija predstavlja kompleksan problem koji se može uspešno rešiti samo ukoliko se čitav niz pojedinačnih koraka pravilno izvrše, počev od izbora ulaznih podataka pa do definisanja modelskih preseka lopatica. Iz tog razloga, brzo i efikasno rešavanje, tzv. inverznog strujnog zadatka moguće je jedino korišćenjem numeričke simulacije strujanja fluida. Metod, predložen u ovom radu, podrazumeva povezivanje rešenja strujanja u meridijanskoj i cirkularnoj ravni. Osnovna pretpostavka, korišćena pri rešavanju postavljenog zadatka odnosi se na osnosimetričnost strujnog polja. U skladu sa metodom Bauersfelda, projektovanja lopatica radnog kola izvršeno je u iterativnom postupku uz korišćenje relacija koje povezuju brzinsko polje sa geometrijskim parametrima lopatice. Posebna pažnja u radu je posvećena definisanju funkcionalne zavisnosti razmene enrgije od ulazne do izlazne ivice lopatice radnog kola. $\mathrm{Na}$ kraju rada prikazan je primer dizajniranja lopatica pumpnog kola.

KLJUČNE REČI: hidraulična transmisija, osnosimetrično strujanje, razmena energije, projektovanje, lopatica 


\title{
DESIGN METHOD FOR HYDRODYNAMIC TORQUE CONVERTER
}

\author{
Dobrica Milovanović, Dušan Gordić, Vladimir Vukašinović, Mladen Josijević
}

\section{INTRODUCTION}

A hydrodynamic torque converter is a type of fluid coupling which transmits power from the engine shaft to the transmission shaft. It is a crucial component in the drivetrain of a vehicle equipped with an automatic gearbox. A typical torque converter consists of the three major components: pump, turbine, and stator (Figure 1). A pump is attached to the engine shaft (prime mover) while the turbine is connected to the transmission shaft. The stator, which is placed between the pump and the turbine, redirects the returning fluid from the turbine to the pump. A one-way clutch is used along with the stator to either lock or unlock the stator depending on the fluid direction (whether it hits the front or back of the stator's vanes). Thus, the pump is used to energize the working fluid which then drives a turbine and returns the fluid to the pump through the stator in a closed circuit [1]. As its name implies, the stator is normally stationary but in most modern torque converters it is usually fitted with a one-way clutch. The torque converter plays an important role in transmitting the engine's torque during the multiplication (converter) and coupling (lock-up) modes. It greatly improves vehicle launch characteristics and passenger comfort [2], thus improving the overall drive ability of the vehicle.

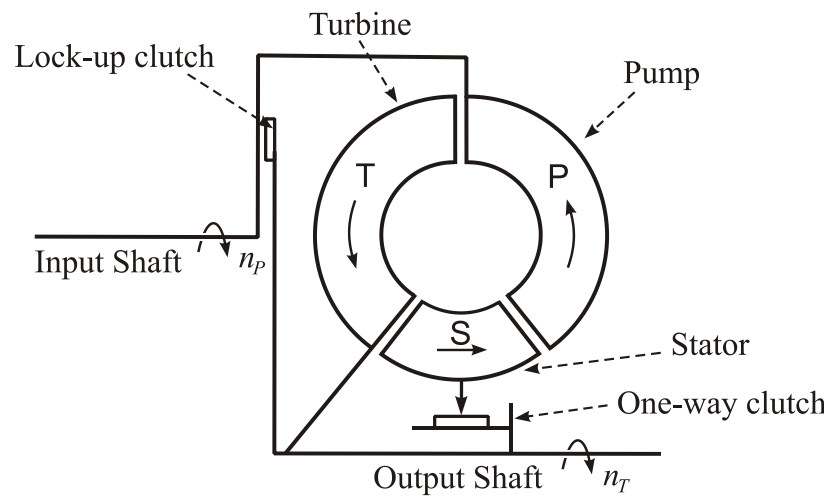

Figure 1. Cross section of a torque converter

\section{BACKGROUND}

A mathematical formulation of the flow field (a direct problem of turbomachinery) inside a torque converter has been developed and published by number of authors, among the others by Kotwicki [3], Hrovat and Tobler [4] and Ejiri and Kubo [5]. The calculation models of the hydrodynamic torque converter have been widely discussed by Migus et al. [6].

The design of the pump (Figure 2) and turbine impeller blades, in general, is the problem of solving the inverse stream task. This problem means obtaining the blade shape on the basis of an already defined stream field, in relation to the given characteristic of the turbomachinery [7]. Concerning the inverse design of turbomachinery blades many papers were published in past years [8]. For the difficulty of inverse problem these models were developed basically under assumption of inviscid flow considering that the effect of fluid viscosity mainly dominates in a thin layer near to solid boundaries in actual machines [9]. 
Based on Wu's theory of two-type stream surfaces [10], quasi three-dimensional (Q3D) inverse models were developed by iterative calculation of a mean hub-to-tip $(S 2 m)$ stream surface and a series of blade-to-blade $(S 1)$ stream surfaces [11]. Q3D inverse methods based on $S 1$ surface or $S 2 m$ surface were extended to various type of turbomachinery [12]. Chen et al. [13] and Borges [14] presented a method for solving the inverse (design) problem of blade cascade flow on the blade-to-blade stream surface of revolution on the basis of the fundamental equations of fluid dynamics.

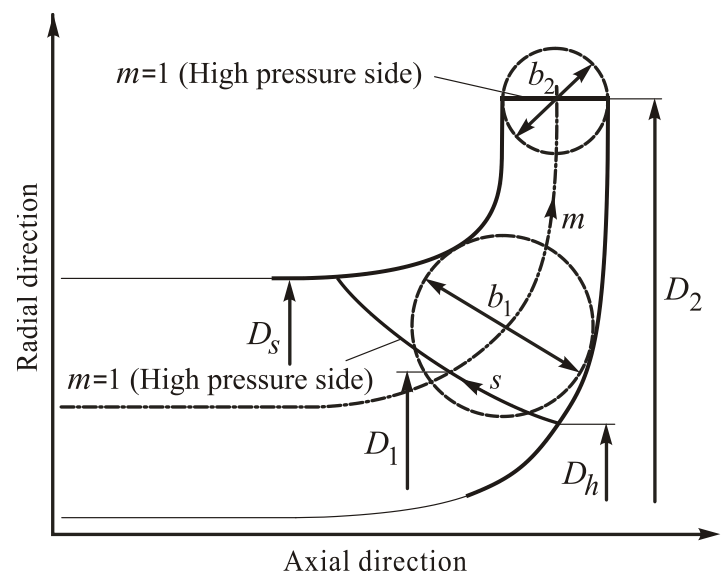

Figure 2. Sketch of pump impeller meridional plane $(S 2 m)$

Because of the complexity of stream phenomena in turbomachinery, the solution of a threedimensional flow equation presents a formidable problem. In general, the flow is unsteady, viscous and compressible and subjected to complicated boundary conditions [15]. Even assuming that the flow is steady and inviscid, the problem still remains very difficult.

In order to obtain the solution of the inverse problem in hydraulic turbomachinery Barlit [16] proposed some assumption that should simplify the problem.

The first assumption is neglecting the viscous characteristic of a working fluid, which enables the use of the theory of the inviscid and incompressible fluid. Figure 3 shows a justification of this assumption. According to Kanavagh [17] the velocity profiles for potential flow and turbulent flow coincide well (Fig. 3).

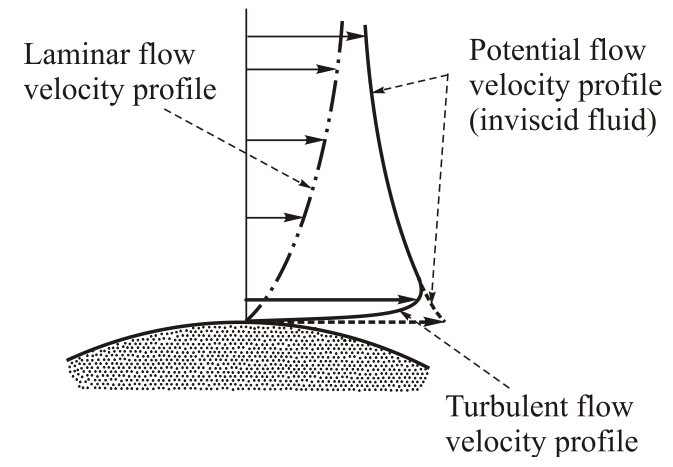

Figure 3. Flow velocity profiles showing influence of the boundary over a range of

Reynolds number from laminar to potential flow 
The second assumption presents neglecting the unsteadiness of the flow that is caused by the finite number of impeller blades. The third assumption in solving the inverse problem in turbomachinery is the simplification of real three-dimensional flow to the quasi-twodimensional flows. This is achieved by taking the mean value of the flow equations with respect to tangential coordinate. This way, the flow in the impeller can be considered as a sum of two components of quasi-two-dimensional flow, as follows:

1. flow in the meridional plane

2. flow in blade-to-blade surfaces

More advanced, three dimensional approaches for the solution of an inverse problem are presented by Chen et al. [18] and Yang et al. [19].

\section{THE FLOW PROBLEM FORMULATION}

The flow in blade-to-blade surfaces can be considered as two-dimensional only for solution of the direct flow problem. In the case of the inverse flow problem that approach increases a problem complexity. For that reason, in this paper, instead of two-dimensional flow, onedimensional flow is considered. In order to correct this assumption in the calculation procedure the corresponding coefficients, which take into account the difference between the simplified flow model and real flow, are introduced.

In accordance with the usual methodology for inverse problem solution with the assumption mentioned, design procedure can be divided into two phases:

1. Solution of the meridional flow in order to define the axially symmetric flow surfaces.

2. Definition of the basic geometric characteristics of the cascades of space profile on the axially symmetric flow areas defined in the previous step.

In this paper, the mathematical model for inverse problem solution is based on the Bauersfeld method [20], which is commonly used in the design of mixed flow type impellers. The Bauersfeld method considers potential meridional flow $\left(\Omega_{u}=0\right)$ and during the procedure, impeller blades are considered as infinitely thin vortex areas (Figure 4).
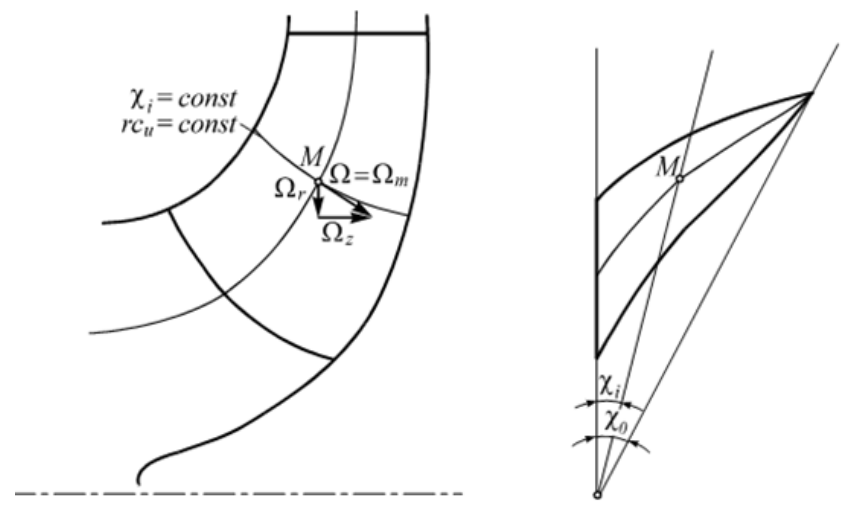

Figure 4. Vortex line and corresponding blade for $\Omega_{u}=0$

In the case of the potential meridional flow vortex vector

$$
\Omega=\Omega_{m}=\Omega_{r}+\Omega_{z}
$$

lies in the meridional plane and from the vortex line equation [20] in the meridional plane: 


$$
\Omega_{r} d z-\Omega_{z} d r=0
$$

after the introduction of the vortex components,

$$
\Omega_{r}=\frac{\partial\left(r c_{u}\right)}{r \partial z} \quad \text { and } \quad \Omega_{r}=-\frac{\partial\left(r c_{u}\right)}{r \partial r}
$$

follows

$$
\frac{\partial\left(r c_{u}\right)}{r \partial z} d z+\frac{\partial\left(r c_{u}\right)}{r \partial r} d r=0
$$

or

$$
r c_{u}=\text { const. }
$$

From equation (4) it follows that the vortex value $r c_{u}$ along the vortex line is constant. Because the vortex line lies in the meridional plane and belongs to the blade, it will coincide with the section line of the blade and the corresponding meridional plane (radial blade section), $\chi_{i}=$ const. Thus, the vortex value $r c_{u}$ in the impeller is changed only from one radial section to another, which can be expressed as:

$$
r c_{u}=f(\chi)
$$

Outside the impeller, in the potential flow case, the vortex value is constant. According to the equations (4) and (5) that is possible only if the inlet and outlet edge of the blade lies in the meridional planes.

The design of the impeller blades is performed using relations between velocity components and geometrical blade parameters. Taking into account the conditions for the Bauersfeld method $\left(\Omega_{u}=0, r c_{u}=\right.$ const. along the radial blade sections), this equation takes the relatively simple form [20]:

$$
d \chi=\frac{r c_{u}-r^{2} \omega}{r^{2} c_{m}} d s
$$

\section{DESIGN OF THE IMPELLER BLADES}

\subsection{Determination of the meridional flow}

The choice of the meridional flow type and method for its forming is the first step for the determination of the meridional flow. In this case adoption of the Bauersfeld method for inverse procedure solution means the adoption of the potential meridional flow. It is known that potential flow in the meridional planes is described with the Stokes equation [21]:

$$
\frac{\partial}{\partial r}\left(\frac{1}{r} \frac{\partial \Psi}{\partial r}\right)+\frac{\partial}{\partial z}\left(\frac{1}{r} \frac{\partial \Psi}{\partial z}\right)=0
$$

Solution of this equation is obtained using the finite element method [22]. That gives the values of the stream function in nodal points. The accuracy of the results of the calculation is defined by fineness of the finite element mesh, i.e. by the number of "the partial impellers".

Further, the lines $\Psi=$ const. are defined using spline interpolation (Figure 5) and the values of the meridional velocities are calculated using the expressions,

$$
c_{r}=\frac{\partial \Psi}{\partial z}, \quad c_{z}=-\frac{\partial \Psi}{\partial r}
$$




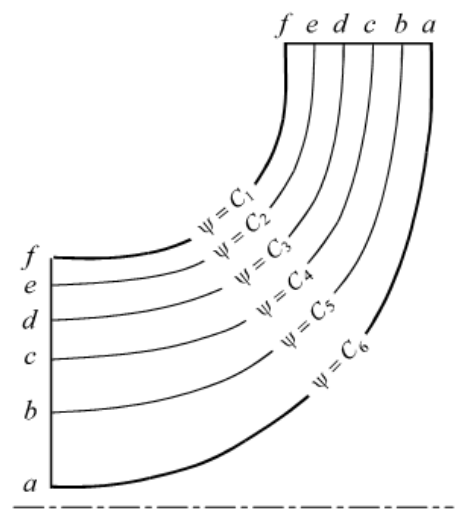

Figure 5. Streamline distribution for a potential meridional flow

\subsection{Design of the impeller blades for potential meridional flow}

For design of the impeller blade on the basis of equation (6), i.e. obtaining its radial sections, it is necessary to know the distribution of the tangential component of the absolute velocity $c_{u}$ along the meridional streamlines, (all other values are defined during the solution of the meridional flow). Because the value of the velocity $c_{u}$ is directly related to the energy balance between the fluid and impeller blades, it must be explicitly defined before the blade design itself. The whole procedure of the impeller blade design can be divided into two phases:

1. Definition of the functional law of the energy interchange in the impeller,

2. Definition of the blade shape which allows the defined law of the energy interchange.

\subsubsection{Determination of functional law of the energy interchange in the impeller}

The calculation of this relation is performed based on the condition that in the impeller with an already defined blade angle $\chi_{0}$ in the circular plane the energy interchange has to be constant. Because the blade angle $\chi_{0}$ does not define the exact functional law of energy interchange, in general, there is some freedom in this procedure related to the curve type which define the mentioned law. On the other hand, on the basis of the present experience in the design of the impellers there some requirements which have to be taken into account if we want that the newly-designed impeller has good energy characteristics. Having this in mind, in order to achieve a good solution, in this paper the following conditions are imposed:

- $\quad$ along any meridional streamline the equal energy amount is interchanged

- the energy interchange between the fluid and the blades is continuous

- the biggest energy amount is interchanged near the outlet blade edge.

In accordance with the mentioned conditions, Figure 6 gives possible functional laws of energy interchange from inlet to the outlet of the impeller. The analytical expression which corresponds to the conditions mentioned above, and to the graph shown in Figure 6, can be described by the following analytical form [23]: 


$$
Y_{t h}=Y_{t h 0}\left[1-\left(1-s / s_{0}\right)^{m\left(\frac{s}{s_{0}}\right)^{k}}\right]
$$

where $k$ is the coefficient of curve type chosen at the beginning of the design procedure and $m$ is the coefficient formed during the procedure.

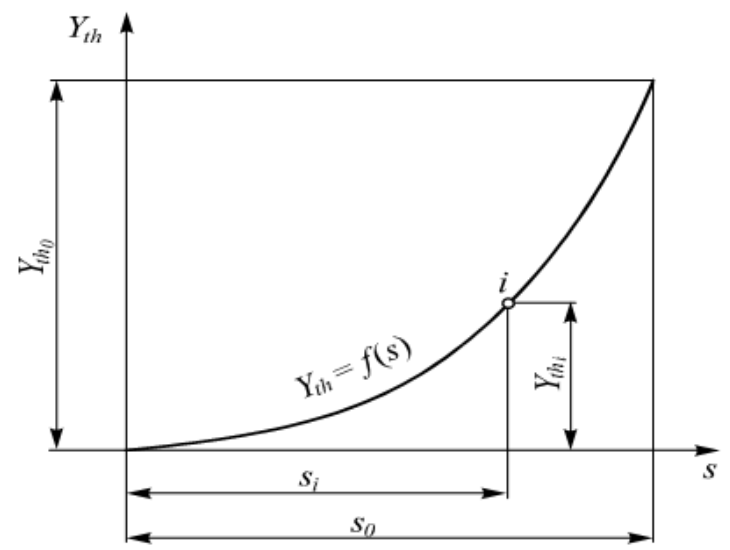

Figure 6. A convenient form of the energy interchange in the impeller

Determination of the energy interchange law, in this case, means determining the value of exponent $m$ in expression (9), based on the condition that along considered meridian streamline inside impeller energy interchange is $Y_{t h 0}$, for adopted blade angle $\chi_{0}$. The position of the meridional streamline inside the impeller and its length are defined by the prescription of the shape of the inlet and outlet edge of the blade in the meridional plane. A global solution of this problem is described below.

Adoption of the initial (free chosen) value of exponent $m$ presumes the exact law of the energy interchange and, on the basis of the Euler equation, the distribution of the tangential velocity component in the impeller. By dividing the meridional streamlines into $n$ equal parts $\Delta s$ (each can be considered as an elementary impeller), and finding corresponding angles $\Delta \chi_{i}$ (using equation (6)) and summing these, the total value of the angle $\chi$ in the circular plane can be calculated for proposed energy interchange law. This value is compared with angle $\chi_{0}$ and in the case that difference between them is greater than the prescribed value $\varepsilon \chi$ the iterative procedure is established until the convergence of exponent $\mathrm{m}$ is achieved.

In the mentioned procedure, from Euler equation for a finite number of blades,

$$
Y_{t h 0}=u_{2} c_{3 u}-u_{1} c_{0 u}
$$

and supposing zero inlet whirl $\left(c_{0 u}=0\right)$, the value of the outlet velocity $c_{3 u}$ is defined by

$$
c_{3 u}=\frac{Y_{t h 0}}{u_{2}}
$$

The peripheral velocity $c_{u}$ inside impeller is determined from the actual energy interchange law (9), by the expression

$$
c_{u \infty i}=\frac{Y_{t h i}}{\omega r_{i} \varepsilon_{i}}
$$

The coefficient $\varepsilon_{i}$ is calculated by Pfleiderer formula [24]: 


$$
\varepsilon_{i}=\frac{1}{1+(0.6 \div 1.0)\left(1+\beta_{L i} / 60\right) \frac{r_{i}{ }^{2}}{z S}}
$$

where static moment $\mathrm{S}$ of the meridional streamline inside impeller is calculated by

$$
S=\int_{r_{1}}^{r_{i}} r d s
$$

while blade angle $\beta_{L i}$ in the considered point follows from velocity triangle

$$
\beta_{L i}=\arctan \frac{c_{m i}}{u_{i}-c_{u i}}
$$

The meridional velocity for finite thickness is calculated using the expression,

$$
c_{m i}=\frac{c_{m i \infty}}{1-\frac{z \delta_{i}}{2 \pi r_{i} \sin \beta_{L i}}}
$$

where $\delta_{i}$ is calculated from the corresponding blade thickness distribution along streamline inside the impeller

$$
\delta_{i}=f(s)
$$

and length of the blade profile is given by

$$
l_{i}=\sum_{k=1}^{i} \frac{\Delta s}{\sin \beta_{L k}}
$$

\subsubsection{Determination of the blade shape}

Under the condition defined by the Bauersfeld method, the vortex $r c_{u}$, i.e. stream energy in the impeller is changed only from one meridional plane to another. If the inlet edge of the blade lies in the meridional plane, the points on different meridional streamlines for equal energy interchange amount will lie on the meridional plane (another one) as well. Because of this, by connecting the ends of corresponding values $s_{i}$ on the different streamlines, the line that lies at the meridional plane is obtained. That line presents a section of the blade and the corresponding meridional plane (so-called radial section of the blade). If the number of radial sectiones is large enough, the corresponding blade shape is defined.
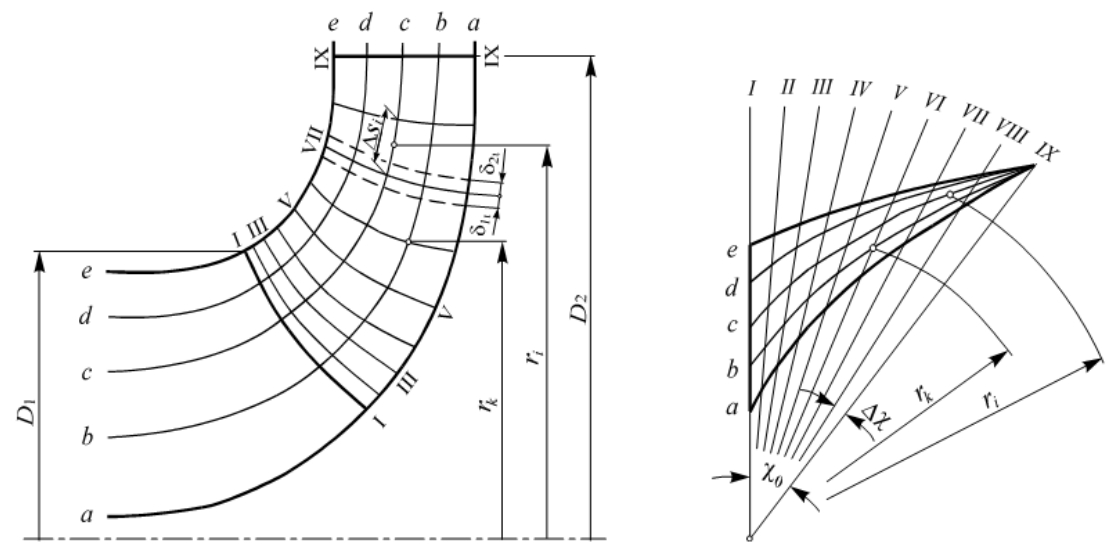

Figure 7. Radial section of the blade

The procedure of determination of the radial blade sections starts with a division of blade angle $\chi_{0}$ into $n$ equal parts (Figure 7): 


$$
\Delta \chi=\frac{\chi_{0}}{n}
$$

The number $n$ depends on the desired precision of the solution. Value of the cuts $\Delta s_{i}$ on meridional streamline (for the correspond angle $\Delta \chi$ ) is given by expression (6):

$$
\Delta s_{i}=\frac{r_{i} c_{m i}}{r_{i} \omega-c_{u i}} \Delta \chi
$$

The calculation procedure is performed in an iterative manner as is shown in the previous section.

For the production of the blades and models for its control, it is more convenient to define the blade using its model sections. For this reason, the system of circular planes (lines 0 - 0 , $1-1, \ldots$ in Figure 8) is used. The points of intersection of these lines with radial blade sections are defined in a circular plane with radius $r_{i j}$ and angle $\chi_{i}$.
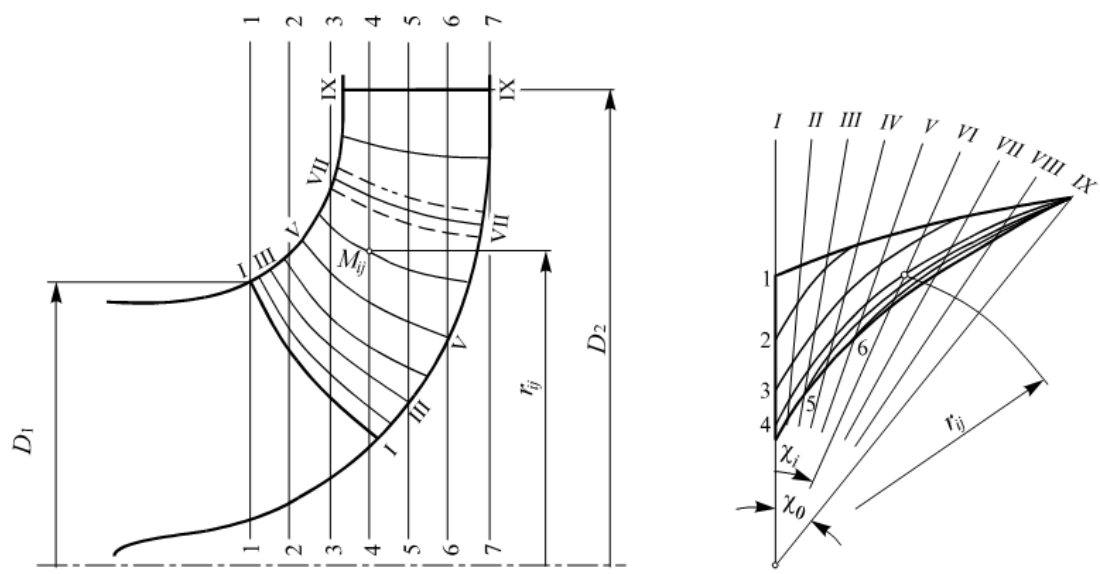

Figure 8. Determination of model sections of the impeller blade

Figure 8 shows the impeller blade design for the following basic parameters:

$Y=360 \mathrm{~J} / \mathrm{kg}, Q=0.3 \mathrm{~m}^{3} / \mathrm{s}, n=1000 \mathrm{rpm}, D_{1}=0.27 \mathrm{~m}, D_{2}=0.36 \mathrm{~m}, b_{1}=0.095 \mathrm{~m}, b_{2}=$ $0.055 \mathrm{~m}$.

\section{CONCLUSION}

The solution method developed in the paper, based on free vortex design, involves the linking of meridional and blade-to-blade solutions. The method which employs a finite element techniques has been developed for determining the blade-to-blade flow of an incompressible non-viscous fluid through a rotating turbomachine blade row.

In accordance with Bauersfeld method, the design of impeller blades is performed in iterative manner by using relationships between velocity components and geometrical blade parameters. The applied procedure allows a very fast design of the blade of the hydrodynamic transmissions for the defined input data.

The presented method is shown in case of pump impeller blade, but with minor changes it can be used for the design of the turbine which is the second component of hydrodynamic torque converter. 


\section{REFERENCES}

[1] Adibi, A. H., Lashgarian A. N., McPhee, J.: "Modeling Torque Converter Characteristics in Automatic Drivelines: Lock-up Clutch and Engine Braking Simulation", ASME 2012 International Design Engineering Technical Conferences, American Society of Mechanical Engineers, 12PFL / 0362, pp. 359/367, Chicago, 2012.

[2] Mercure, R. A.: "Review of the automotive torque converter", SAE Technical Paper 790046, 1979.

[3] Kotwicki, A. J.: "Dynamic Models for Torque Converter Equipped Vehicles", SAE Technical Paper Series, International Congress and Exposition, Detroit, Michigan, February 22-26, 1982.

[4] Hrovat, D., Tobler, W. E.: "Bond Graph Modeling and Computer Simulation of Automotive Torque Converters", Journal of Franklin Institute, Vol. 319, 1985, pp. 93 114.

[5] Ejiri, E., Kubo, M.: "Performance analysis of automotive torque converter elements," Journal of Fluids Engineering, Vol. 121, No. 2, 1999, pp. 266-275.

[6] Migus, M., Kęsy, A., Kęsy, Z.: "Flow Simulation in Hydrodynamic Torque Converter" Technical Transactions, Mechanics, Vol. 114, No. 7, 2017, pp.165-173.

[7] Jenkins, R. M., Moore, D. A.: “An inverse calculation technique for quasi-threedimensional turbomachinery cascades," Appl. Math. Comput., Vol. 57, No. 2, 1993, pp. 197-204.

[8] Peng, G.: “A Practical Combined Computation Method of Mean Through-Flow for 3D Inverse Design of Hydraulic Turbomachinery Blades", Journal of Fluids Engineering, Vol. 127, No. 6, 2006, pp. 1183-1190.

[9] Esch, B. P. M., Kruyt, N. P.: "Hydraulic Performance of a Mixed- Flow Pump: Unsteady Inviscid Computations and Loss Models," ASME Journal of Fluids Engineering, Vol. 123, No. 2, 2001, pp. 256-264.

[10] Wu, C. H.: "A General Theory of Three-Dimensional Flow in Subsonic Turbomachines of Radial-, Axial-, and Mixed Flow Types," NACA TN-D2604, 1952.

[11] Peng, G., Fujikwa, S., Cao, S.: “An Advanced Quasi-Three-Dimensional Inverse Computation Model for Axial Flow Pump Impeller Design," Proceedings of the XIX IAHR Symposium-Hydraulic Machinery and Cavitation, H. Brekke et al., eds., World Scientific, Singapore, 1998, pp. 722-733.

[12] Peng, G., Cao, S., Ishizuka, M., Hayama, S.: "Design Optimization of Axial Flow Hydraulic Turbine Runner Part I: An Improved Q3D Inverse Method,” International Journal for Numerical Methods in Fluids, Vol. 39, No. 6, 2002, pp. 517-531.

[13] Chen, N., Zhang, F., Li, W.: "An Inverse (Design) Problem Solution Method for the Blade Cascade Flow on Streamsurface of Revolution", ASME Journal of Turbomachinery, Vol. 108, 1986, pp. 194-199.

[14] Borges, J. E.: “A Three-Dimensional Inverse Method for Turbomachinery: Part 1", ASME Journal of Turbomachinery, Vol. 112, 1990, pp. 346-354.

[15] Chen, N.: "Two- Dimensional Aerodynamic Inverse Problem Solution Study in Turbo-machinery", Hoboken, NJ: John Wiley \& Sons, 2010.

[16] Barlit, V.: "Hydraulic Turbomachines" (in Russian), Kiev, 1977.

[17] Kanavagh, P.: „Through-Flow Solution for Axial Turbomachine Blade Rows”, Ph. D. thesis, Iowa State University of Science and Technology, 1966. 
[18] Chen, C., Zhu, B., Singh, P., Choi, Y.: "Design of a Pump-Turbine Based on 3D Inverse Design Method", Journal of Fluid Machinery, Vol. 18, No 1, 2015, pp. 20-28.

[19] Yang, J., Liu, Y., Wang, X., Wu, H.: “An Improved Steady Inverse Method for Turbomachinery Aerodynamic Design", Journal Inverse Problems in Science and Engineering, Volume 25, No 5, 2017.

[20] Yang, J., Liu, Y., Wang, X., Wu, H.: "An Improved Steady Inverse Method for Turbomachinery Aerodynamic Design", Journal Inverse Problems in Science and Engineering, Volume 25, No 5, 2017.

[21] Andersson B., Andersson R., Hakansson L. et al.: "Computational Fluid Dynamics for Engineers", Cambridge: Cambridge University Press, 2012.

[22] Dmitri K. D., Hämäläinen, J.: "Finite Element Methods for Computational Fluid Dynamics: A Practical Guide", Philadelphia: University City, SIAM-Society for Industrial and Applied Mathematics, 2014.

[23] Milovanovic, D.: "Contribution to the Solution of the Inverse Problem in Hydraulic Turbomachines", MSc thesis, Faculty of Mechanical Engineering, Kragujevac, 1997.

[24] Pfleiderer, C., Peterman, H.: "Stromungsmaschine”, Springer-Verlag, Berlin/ Gottingen/ Heidelberg, 1964. 